\title{
DISPERATA VITALITÀ. LOS RELATOS DE LA PASIÓN. LA IDEOLOGÍA DEL RELATO. POESÍA, EN FORMA DE DUDA
}

\section{Román Reyes}

Universidad Complutense de Madrid

EMUI_EuroMed University, Roma

Il crollo del presente implica anche il crollo del passato. La vita è un mucchio di insignificanti e ironiche rovine ... 1

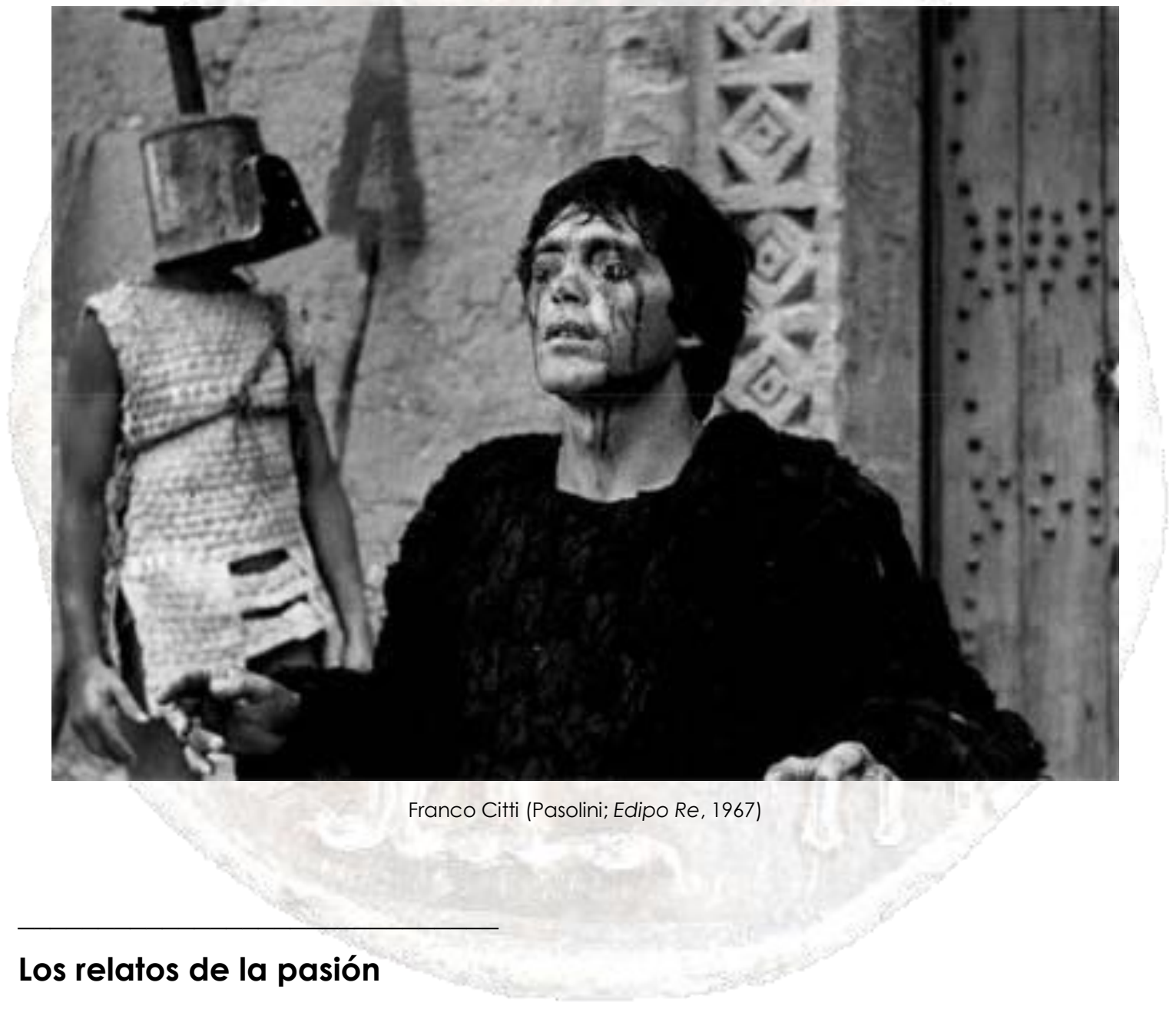

01.- No hay significante. La ironía de las ruinas es la no-verdad. Huellas de la sacralidad primitiva. Cosas que no son más realidad que su decadente testimonio. Significados sin sintaxis. Montón de vida, fragmentos de historias sin narrar. Fulgores a medio percibir, de épocas sin instante.

\footnotetext{
1 Pier Paolo Pasolini, Abiura della Trilogia della vita, 1975
} 
La insignificancia es que sólo sea palabra en el tiempo². El tiempo de ser usada. De pertenecer a un lenguaje efímero. Diverso, pero útil. El interés del hablante, que habla contra el discurso de la homologación. Hacia la indiferencia de la cosa, que no es palabra-persona. Sólo arte de un oficio. El hacer del poeta (y del loco), que habla realidad, hablando palabra en el tiempo (de nuestra vida), regalándonos la emoción (la luz y la melodía) de ese tiempo. Que es la representación más inmediata: la propia epifanía, con el color de la necesidad.

La ruina es el abandono del tiempo. En el tiempo. La huida, la traducción del significado de un lugar. El puesto de una cosa. Que sólo sueña, como cosá significada, quien sea su titular.

El tránsito es también salto. Y destino. Sobre la soledad, que el silencio separa. Que es vacío en el olvido, actualidad posible. La separación es el nombre de la locura. El riesgo del camino (y del andar), entre lo que sucede y lo que fue acontecimiento soñado. Hacia el instante pasado, que es término. Hacia una meta, que no es fin, sino espera.

02.- La mayoría de edad de un relato (1999-2017), como sistema de fragmentos aleatoriamente relacionados, deja el sueño en entredicho. Porque es certeza de duda. Inestabilidad de escritura. Soledad del lector, que sólo se lee a sí mismo ante un espejo geométrico. Un sueño en entredicho. Como el descanso del poeta. La agrafía del sacerdote. Blasfemia de diosas, que humanizan belleza.

Relatos de la pasión. $\mathrm{O}$, non è la felicità che conta?. Non è per la felicità che si fa la revoluzione?3. Por el amor de saberlo, al preguntar. Las leyes del futuro sólo se promulgan desobedeciendo, la ideología burguesa. El discurso del Poder. Pero, desobedeciendo también la ideología del propio relato. Por el amor de dudarlo, al saberlo.

Releer mis propios textos. Con temor. Temblando de pecado. Textos releídos, por pecadores vulgares. A quienes no sé si la profecía del pasado, que subyace (tras la mirada del lector), salva de la duda. Hablo (quise hablar) entre un pasado perdido y un futuro posible. Sin saber (ahora estoy seguro) si hablaba desde esa posibilidad hacia oportunidades de la memoria. Que no llegaran a ser siquiera anuncio de actualidad.

Porque sólo me consta to que oculto, amo ferocemente, disperatamente la vita. E credo che questa ferocia, questa disperazione mi porteranno alla fine. Amo il sole, l'erba, la gioventù. L'amo re per la vita è divenuto per me un vizio più micidiale della cocaina. lo divoro la

\footnotetext{
2 Antonio Machado: Ni mármol duro ni eterno, / ni música ni pintura, / sino palabra en el tiempo

3 Pier Paolo Pasolini, "La rivoluzione antropologica in Italia", Scritti Corsari, 11 luglio 1974
} 
mia esistenza con un appetito insaziabile. Come finirà tutto ciò? Lo ignoro 4

\section{La ideología del relato}

Lavoro tutto il giorno come un monaco / e la notte in giro, come un gattaccio / in cerca di amore... Farò proposta / alla Curia d'esser fatto santo. / Rispondo infatti alla mistificazione / con la mitezza. Guardo con l'occhio / d'un' immagine gli addetti al linciaggio. / Osservo me stesso massacrato colsereno / coraggio d'uno scienziato. / Passivo come un uccello che vede / tutto, volando, e si porta in cuore / nel volo in cielo la coscienza / che non perdona 5 .

03. Hoja de ruta implacablemente burguesa (tener-poseer-consumirdestruir), nunca quise y odié los espacios reservados para la creatividad y el placer. Mis burdeles fueron siempre espacios abiertos, contaminados de la inmediatez, de la existencia en su más desnuda actualidad. Mis pérdidas fueron justas, diversas, porque mi extravío jamás fue infracción tolerada.

Para un intelectual incómodo (como siempre me he sentido) la vida no soporta la reducción a muestra o emulación en laboratorios. Porque la vivir (estando en la historia) es mucho antes mostración, epifanía (sein, da-sein, so-sein'6), que representación, imagen o idea (textos sin pasión, puro academicismo). Me importó (y sigue importando) mucho más las fronteras del saber: por qué y para qué se ponen límites a la realidad. Y una realidad metodológicamente fragmentada es falacia, fictum, trampa. Nunca creí, por ello, en la especialización, o esa eufemística división del trabajo intelectual. En el encierro desaparecen los matices, la singularidad-otra, la diferencia. En el encierro todo es repetición. De lo mismo en lo mismo. El encierro es lo que es: clausura o reclusión ideológica. La pasión, sin embargo, no admite fronteras. Hacia lo público desde l'intérieur, desde l'extérieur hacia la privado.

04.- Cómo eran las cosas antes de que fuese cosa, de que estuviera rodeado de cosas, siendo cosa entre cosas. Las cosas que eran antes, son ahora para mí sólo huellas o ruinas cargadas de sentido.

Pero el sentido de las cosas que eran antes de que fuera cosa es sueño. Que otros soñaron, dentro del sueño que es el devenir cosa. El relato de

\footnotetext{
${ }_{4}$ Pier Paolo Pasolini, Intervista rilasciata a Louis Valentin e pubblicata su Lui, n. 1., giugno 1970

5 Pier Paolo Pasolini, Poesie mondane, 1962

${ }^{6} \mathrm{Si}$ se me admite un forzado paralelismo con la existencia (sein) heideggeriana
} 
palingénesis, como sueño cumplido en el futuro. La voluntad de preferencia en el pasado lo es (preferencia y voluntad) si esa preferencia es fuerza que anticipa las condiciones del progreso (nacer a la muerte): La adaptación al medio socio-cultural, político-económico y ecológico del presente anticipado.

Porque el poeta no predice (... osservo me stesso massacrato col sereno coraggio d'una scienziato...), advertirlo siquiera es convertirse en presa fácil del burgués. Chivo expiatorio en la reserva, si piensa que la muerte (estética) de la poesía puede reconvertirse en beneficio propio, adornando los museos del horror: Lengua y Cultura de Estado.

Dunque io mi sto adattando alla degradazione e sto accettando I' inaccettabile. Manovro per risistemare la mia vita. Sto dimenticando com' erano prima le cose. Le amate facce di ieri cominciano a ingiallire. Mi è davanti - pian piano senza più alternative - il presente?.

\section{Poesía, en forma de duda}

Del mondo antico e del mondo futuro era rimasta solo la bellezza, e tu, povera sorellina minore, te la sei portata dietro como un sorriso obediente 8

05.- Desde mi lengua, de poeta de las cosas, se ve tu belleza. Desde la lengua de tu belleza llamo a las cosas por el nombre de su pasado. Aprendí a hablar la historia de mis cosas.

Desde mi lengua, de poeta de las cosas, se ve el mar de tu cuerpo, Aprendí a llamar soñar la melodía de tu metáfora. Dibujando realidad sobre un poema. Que habla imagen, gritando soledad. Por no guardar silencio, rebeldía de futuro.

Desde la actualidad de mi destino aprendí a escribir sueño. Mientras esperaba que sucediera el cuerpo de mi lengua.

Desde mi ventana. Desde mi duda. Formas de mi poesía no poética. Formas de mi pasión laica. Por vivir poesía.

Desde la lucha de tu seductora duda. Cuerpo a poema. Metáfora a cuerpo. Muerte a muerte.

06.- Oculto el nombre de las cosas. Que es ocultar mi belleza inexpresiva. Me oculto tras el nombre, pronunciado en el origen. Me

\footnotetext{
7 Pier Paolo Pasolini, Abiura dalla Trilogia della vita, 1975. Publicado póstumamente el II Corriere della Sera el 9 de Noviembre del mismo año. Posteriormente incluido en Lettere luterane, Einaudi, Torino, 1976

8 Pier Paolo Pasolini, 'Marylin', La Rabbia, 1963
} 
oculto sin relatos, sin la historia de mi juventud. Que fue futuro sin pasado. Oculto la diversidad de mi poesía. El nombre de las cosas es mi existencia, elocuentemente muda. Locura de metáfora.

El eco es la mirada del transeúnte, que pasea cuerpo. Por no militar (gestión de) textos. Llega, después de haber dudado mi cuerpo. La religión de mi diversidad.

(..) Ma in verità in verità in verità / quello per cui tu stesso ti credevi un diverso / non era la tua vera diversità./ La tua vera diversità era la poesia. / È quella l'ultima ragione del loro odio / perché i poeti sono il sale della terra / e toro vogliono la terra insipida./ In realtà, LORO sono contro-natura. / E tu sei natura: Poesia cioè natura. / E così, tu adesso hai tagliato la corda. / (..) ${ }^{9}$

\section{DISPERATA VITALITÀ}

Quella luce era speranza di giustizia: non sapevo quale: la Giustizia. La luce è sempre uguale ad altra luce. Poi variò: da luce diventò incerta alba, un'alba che cresceva ... Cosi l'alba nascente fu una luce fuori dall'eternità dello stile ... Nella storia la giustizia fu coscienza d'una umana divisione di ricchezza, e la speranza ebbe nuova luce ${ }^{10}$.

07.- La vida es un jardín. De sueños de la memoria. En medio de un bosque de relatos, ordenadamente salvaje. La vida es el jardín de los relatos del sueño. Dentro de un bosque de sueños, que crece al ritmo del color de la humedad. Pasión futura de pasado. Al ritmo. Del anuncio de otro sueño, naciendo a la muerte. La vida es el sueño de esos bosques. Y el relato de (la muerte de) ese sueño. El jardín de mi vida es un desesperado sueño. El confuso relato de mi locura.

Mi vida es un jardín de pasiones. Que eros administra. Al ritmo de la duda. Conocer es desvelar el juego. Saber el nombre de lo oculto. Ganar la partida al destino. Sin voluntad de sintaxis. Despejando posiciones. Desde la contradicción. Saber el nombre es descubrir cosas que, a su vez, el nombre oculta. Lo oculto es lo innombrable, la imagen de lo sagrado. Los destellos de la memoria.

La pasión por la pasión de lo mismo es un huésped incómodo. Está ahí. Como la homosexualidad. El deseo de tener, para poseer su belleza, es el deseo de la propia imagen. La pasión huidiza, que el cuerpo del otro me recuerda.

9 Elsa Morante, A P.P.P. In nessun posto, Roma, 13 febbraio 1976

10 La Resistenza e la sua luce e Lacrime furono pubblicate nella sezione La ricchezza (1955-1959) della raccolta La religione del mio tempo, edita da Garzanti nel 1961, ora in P.P.Pasolini, Tutte le poesie, a cura di W.Siti, vol. I, "Meridiani" Mondadori, Milano 2003, pp.944-947 
08.- La memoria de cosas es registro de relatos confusos. Fragmentos, desgarros de historias, que mi cuerpo escribe. Tienen la vida de quien hace memoria. La memoria de las cosas es la lectura de la memoria de cosas. De quienes me precedieron. Haciendo memoria. La mirada sobre las cosas es, por tanto, antropológica. Historia. Y cultura. La estética de la ambigüedad. La ética de la periferia.

Pero las cosas tienen también su propia memoria. Aquello que les hacen cosa y no eco o imagen. Del sueño de una cosa. Aquello que hace de la cosa la memoria que yo hago de las cosas es la acción del medio natural sobre las mismas. Siendo, como soy, memoria no natural.

La vida es descúbrir pasajes. O trazar senderos. Domesticar el tránsito. $O$ la pérdida. Los pasos de la memoria. Desde la actualidad al instante. Que también es sólo paso. Fugaz fragmento. Pretexto. Silencios del lenguaje. Pasión. Belleza prometida. Entre la palabra pronunciada y el nombre del deseo. Y la palabra jamás escrita (hacia el pasado). Leyes del devenir actualidad soñada. Ideología.

Entre lo uno y lo otro. Tensando la muerte. Esperando la ternura, que la poesía anuncia. Sin que la cuerda se rompa. Ser diverso es arriesgar vida. Y el anuncio es sólo el placer del mensaje. El anuncio de la luz, que nunca se apagó para mí. Y estando tan expuesto cuán desapercibido me sentía!

09.- No quería saber más, para saber lo acumulado. Saber es saber hacer. Saber administrar la inocencia. Organizar la gestión del propio phatos. Y la acogida de otros saberes. Procesados. Que son ideología con pasión. O la pasión de saber mirar. Sentir la locura del poeta, que no es la quietud de la sinrazón originaria. El mito de la utopía vs la razón de lo inmediato. La pasión por lo diverso. O el orden de un discurso. Nuevo. Por exclusión de otros impuestos.

La sumisión es dependencia de lengua. Seguridad (tolerada) en el hablar. La resistencia es también seguridad. Y seguridad de todo lo que significa hablar: hablar luz y sombras, hablar lágrimas y sangre, hablar soledad, olvido y locura. Hablar humano. Secuencias de orgasmos de (tensa) existencia. 


\section{La sacralità del consumo come rito}

10.- El nuevo poder, la (falsa) ideología del consumo y de la tolerancia (y del pleno disfrute, consumiendo, dopo la scomparsa delle lucciole'1) ha diseñado una estrategia de mercado: sacar beneficio de la desacralización. Viejo mundo arcaico, rural y campesino, homologado ahora, triste mundo pequeño burgués, tristeza de proletariado periférico, geográfico y social. El nuevo poder, la nueva cultura de masas, se asegura así un dominio sobre las conciencias y un control absoluto de cualquier movilidad (espacio reservado antes a la lglesia).

Il potere non è più infatti clerico-fascista, non è più repressivo. Non possiamo più usare contro di esso gli argomenti - a cui ci eravamo tanto abituati e quasi affezionati - che tanto abbiamo adoperato contro il potere clerico-fascista, contro il potere repressivo. II nuovo potere consumistico e permissivo si è valso proprio delle nostre conquiste mentali di laici, di illuministi, di razionalisti, per costruire la propria impalcatura di falso laicismo, di falso illuminismo, di falsa razionalità.

Si è valso delle nostre sconsacrazioni per liberarsi di un passato che, con tutte le sue atroci e idiote consacrazioni, non gli serviva più. In compenso però tale nuovo potere ha portato al limite massimo la sua unica possibile sacralità: la sacralità del consumo come rito, e, naturalmente, della merce come feticcio. Nulla più osta a tutto questo. Il nuovo potere non ha più nessun interesse, o necessità, a mascherare con Religioni, Ideali e cose del genere, ciò che Marx aveva smascherato' ${ }^{12}$.

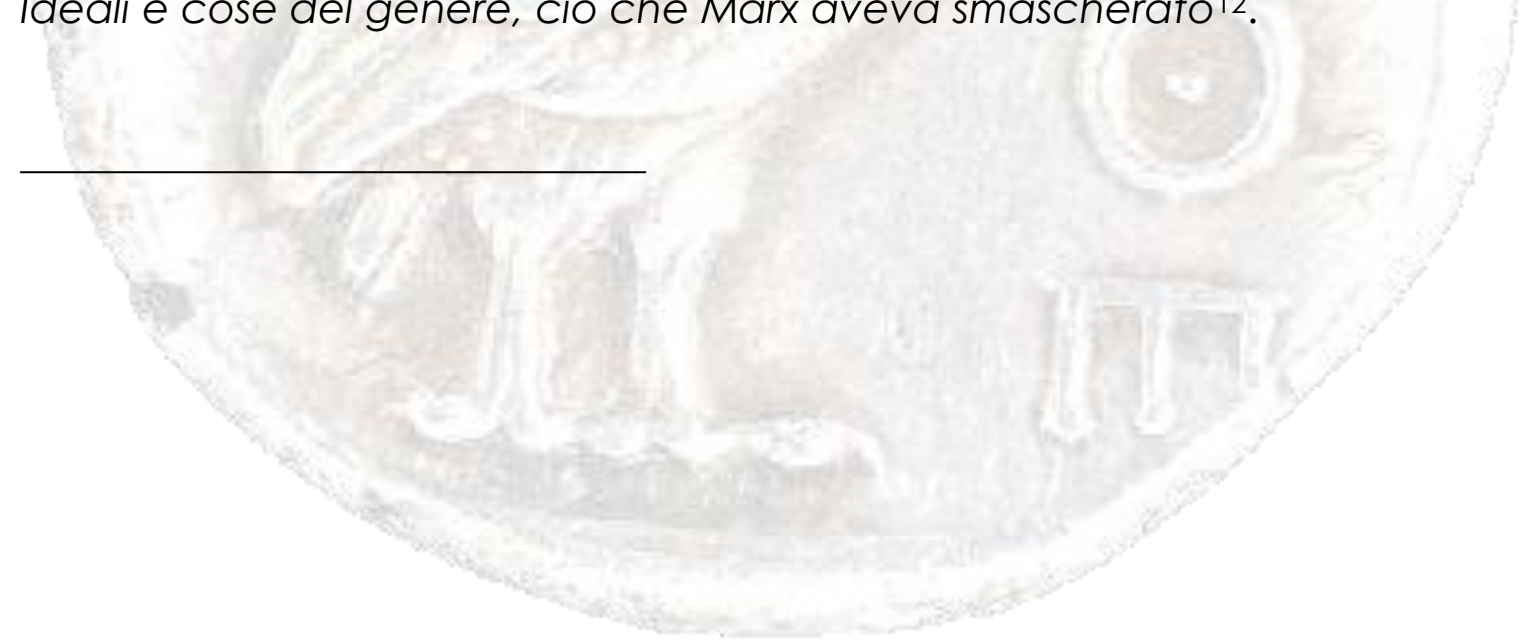

\footnotetext{
11 Pier Paolo Pasolini, "Il vuoto del potere" ovvero "I'articolo delle lucciole", Corriere della Sera, 1 febbraio 1975

12Pier Paolo Pasolini, "Non aver paura di avere un cuore", Corriere della Sera, 1 marzo 1975, in Scritti Corsari
} 


\section{Ciò che non esprimo muore}

Mi tiempo es una secuencia ininterrumpida de instantes, que no perdí en pasado y que vivo ahora en futuro. Demasiada vitalidad, locura de silencio, que es el grito del vacío. Desde el abismo. Entre el cuerpo y el relato erótico de mi poesía. Mi instante es el anuncio de realidad poética. Ese instante, que será tuyo, cuando me leas. Atrápalo. Mi instante es el confuso sueño del relato, que es sueño, sin ser siquiera pequeña muerte (petite morte)13. Que será el sueño de muerte, naciendo a la vida de una interminable secuencia de orgasmos (metáfora soñada, dentro de sueños ajenos)

Ah, forse non diventeranno mai grande, non invecchieranno mai, fermi nella loro intima allegria e grazia. Adulto?. Mai -mai, come l'esistenza che non matura-resta sempre acerba ${ }^{14}$

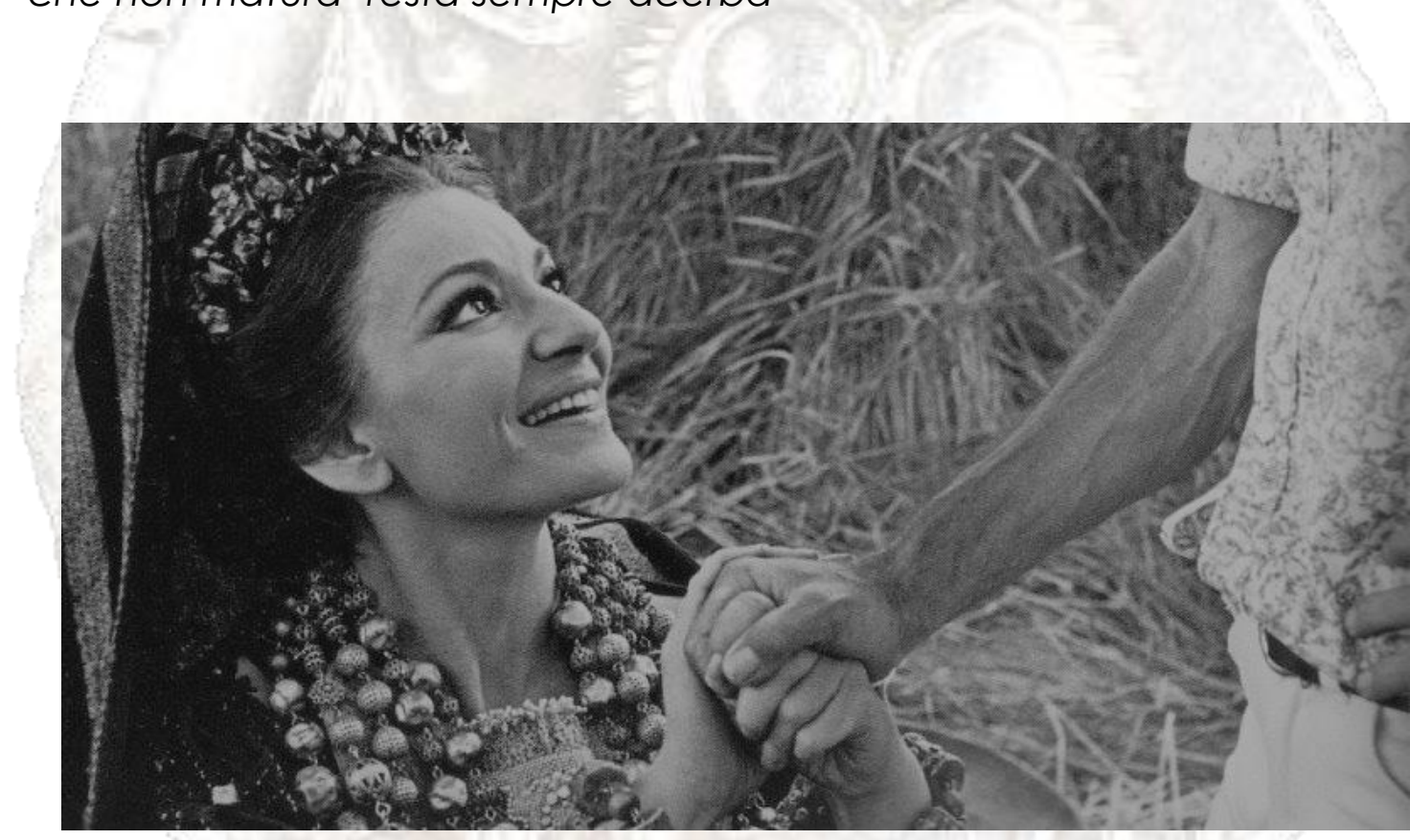

Maria Callas e PPP, (Medea, Cappadocia, Giugno,1969)

Ciò che non esprimo muore. / Non voglio che nulla muoia in me. / II mio orgasmo è consumarmi / fino ai detriti della pazzia / il mio orgasmo è risparmiarmi, / non perdere una lacrima... / Mi scuote una febbre di maniaco / al pensiero di giungere tardi / di perdere un istante: troppa vita / deve affrontare questo vivo / che io nutro senza averne forze ${ }^{15}$.

\footnotetext{
13 Georges Bataille, Les larmes d'Eros: «Le sens de ce livre est, en un premier pas, d'ouvrir la conscience à l'identité de la 'petite mort' et d'une mort définitive. de la volupté, du délire de la mort sans limites».

14 Pier Paolo Pasolini, Roma 1950. Diario

15 Pier Paolo Pasolini, Venti pagine di diario (1948-1949)
} 